\title{
Nurses Perception toward Nursing Workloads and its Effect on Nurses Errors at Benha University Hospital
}

\author{
Hanaa Samir Abd El-Aziz* Elsayad, Mona Mostafa Shazly**, Salwa Ibrahiem Mahmoud* \\ *Nursing Administration, Faculty of Nursing, Benha University \\ **Nursing Administration, Faculty of Nursing, Ain Shams University.
}

\section{ABSTRACT}

Background, Workload in nursing is important for several reasons, workload levels have been shown to influence outcomes such as mortality and morbidity for hospital patients and workload levels have been shown to influence the job retention and job satisfaction of nurses. The study aimed to identify nurses perception toward nursing workloads and its effect on nurses errors in Benha University Hospital. Descriptive design was utilized to meet the aim of this study. The study setting this study was conducted at Benha University Hospital. The study sample was composed of 253 nurses and 34 head nurse. Three tools were used for data collection of this study; Nurses Workload perception Questionnaire, Nurses Errors Questionnaire and Workload Management Questionnaire. The results showed that, $49.4 \%$ of staff nurses had low perception related to nursing workload, $53.4 \%$ of staff nurses had moderate perception related to causes and types of error. In addition all of studied head nurses used promoting performance level method to manage staff nurses workloads. The study concluded that nearly half of staff nurses had low perception related to nursing workload and there was significant positive correlation between nursing workload and nurses errors. The study Recommended that continuous education program for nurses to update their knowledge and skills in order to give quality of nursing care for avoiding the errors related to under staffing.

Key words: Work load - Error - Nursing personnel- perception

satisfaction and causing burnout (Al-

\section{Introduction}

Nursing is a stressful career. Many factors in the work environment contribute to this. Shortage of nurses is one of those factors that makes hospitals short staffed and increases nurses workload. Quality of patient care, as well as adverse nurse outcomes is directly affected by nurses workload. Insufficient staffing leads to difficulties in meeting patient needs and places nurses under increased pressure at work. Heavy workload adversely affects nurses by threatening physical safety, lowering job
Kandari and Thomas, 2008).

Hoonakker et al., (2012) defined workload as the relative capacity to respond and construct that used to describe the extent to which an operator has engaged the cognitive and physical resources required for a task performance. According to Carayon and Gurses ,(2014) workload is a multidimensional and complex construct which is affected by external task demands, environmental, organizational and psychological factors, perceptive and cognitive abilities; nursing workload at 
hospital is related to care needs of patients and to standard of care intended. A range of factors and the size of professional team contribute to workload.

Nurse staffing and nursing workloads are intrinsically linked, so when there are not enough nurses, the workload of each nurse is increased, less time to routine observations, hygiene, wound care, nutrition, patient education, paperwork, counseling, taking rest and meal breaks. Inadequate staffing and overwhelming workloads not only reduce nurses ability to deliver all necessary care, but it also predisposes nurses to increased fatigue and increases the risk of errors. In considering the contribution of workload to patient outcomes, it is important to think not only of the work that nurses do that contributes to patient outcomes, but also the care they do not do, when rushing between too many patients prevents them from providing optimum nursing interventions(Armstrong and Reale,2009).

Nursing workload affects the time specified for different activities among nurses. When the nursing workload is increased, no enough time will be remained for nursing staff to spend for patients health and safety. Excessive workload can also influence on nursing decision making regarding patients care activities resulting in wrong decision making and low quality of care and cooperation. It also causes limitation in nursing inter relationship (Esmaeilil et al., 2015).

Another effect of increased nursing workload is the risk of adverse events and missed nursing care. When a nurse is caught up with in one patients room, another provider might help out with their other patient assignments. This shift from one caregiver to another could result in errors since the new caregiver is not as familiar with the patient. Missed nursing care, or any aspect of required patient care that is omitted (either in part or whole) or significantly delayed, is another possible outcome .The most frequent cause of missed care was reported by Registered Nurse RNs and Unlicensed Assistive Personnel UAP: inadequate staff, urgent patient situations and unexpected rise in patient volume and acuity (Borowski , 2013).

The administration of medication is recognized as a fundamental aspect of the nursing role because it can be associated with considerable risks. Continuous vigilance must be maintained in order to avoid the potential for medication errors. Nursing staff are generally responsible for administering medications to patients and given this unique role, they are able to report medication errors once these have been identified (Sujata et al., 2011).

Nursing errors are sometimes subsumed under medical errors or medication errors with little public or professional awareness of the nature and seriousness of errors that nurses could prevent or cause. Nurses provide the closest and most consistent surveillance of patients. In some situations, institutional and resource conditions for good practice are missing. There may be staffing shortages, poor inter professional communication practices or errors that occur as a result of breakdowns in the institutional support essential to fulfill the minimal professional standards for good nursing practice (Benner et al., 2010). Promptly correct any errors make in documenting on a clients record, know and follow facility policy for correcting errors. Generally, it is acceptable to draw a single line through the mistaken entry so that what was written can still be read (White et al., 2011).

\section{Significant of the study:}

Nursing workload is an important factor in ensuring the safety and quality of care for patients. Increasing workload is one of the main concerns in the field of health and treatment. It is also one of the most important 
stressors among nurses. Excessive workload can lead to adverse outcomes for nurses and other staff, increase in occupational injury, higher job demands and difficult decision making resulting in mental tension and job exhaustion (Esmaeilil et al., 2015).

The heavy workload of hospital nurses is a major problem for the health care system. Nurses are experiencing higher workloads than ever before due to four main reasons; increased demand for nurses, inadequate supply of nurses, reduced staffing and increased overtime and reduction in patient length of stay. So that this study will be concerned with nurses perception toward nursing workloads and its effect on nurses errors at Benha University Hospital.

\section{Aim of the study:}

This study aims to identify nurses perception toward nursing workloads and its effect on nurses errors at Benha University Hospital.

\section{Research Questions} nurses?

1-What are the workloads among staff

2-What are the causes and types of staff nurses errors from their perspective?

3-What are the methods used by head nurses to manage staff nurses workloads from their perspective?

\section{Subjects \& methods:}

Design: Descriptive design was used to carrying out this study.

Setting: The study was carried out at Benha University Hospital in all inpatient departments.

\section{Subjects:}

The subjects of this study consisted of two main groups; namely head nurses and staff nurses.

\section{A-The Head Nurses Group:}

A convenience sample was taken from the above mentioned setting it included all available head nurses 34 who are working in the above mentioned setting during the time of data collection. The subject was selected to meet the criteria that had not less than one year experience in their work setting as a head nurse.

\section{B-The Staff Nurses Group:}

Total Number of staff nurses is 692 who are present in all patient departments at Benha University Hospital.

Sample size: - The sample size was 253 staff nurse were chosen randomly

The equation of sample size is:

$$
\underset{1+\mathrm{n}(\mathrm{e})}{(-\mathrm{N}})
$$

$\mathrm{N}=$ total number of staff nurses at years of job experience who are present at Benha University Hospital. e= Coefficient factor $=0.05$.

Tool of data collection: Three tools were used for data collection

1): - Nurses Workload perception Questionnaire: it was modified by the researcher based on Ali, (2002), Al-Maani, (2006) and Amaar\&Aboelrose, (2006). It contained of two parts:-

Part I: concerned with personal data of staff nurses such as (age, gender, marital status, nursing qualification, years of 
experience in hospital and years of experience in department).

Part II: this part intended to assess nurses perception related to workload. It was consisted of 61 items.

Scoring system: Likert scale with three category was compressed for the purpose of presentation of each item; the responses from agree to disagree were scored respectively from 0-2, (0) disagree and (1) Agree to some extent and (2) agree. Total perception of the studied staff nurses was determined as the follow: - low perception $<60 \%$, moderate perception: $60-<75 \%$ and high perception $\geq 75 \%$.

2): - Nurses Errors Questionnaire: It was modified by the researcher based on Ali, (2002). It included 34 items to assess nurses causes of error, types, reaction toward error.

Scoring system: Likert scale with three category was compressed for the purpose of presentation of each item; the responses from agree to disagree were scored respectively from 0-2, (0) disagree and (1) Agree to some extent and (2) agree.

\section{3): Workload Management} Questionnaire: It was modified by the researcher based on Ali, (2002); Mcphaul et al., (2008) and Samra et al., (2012).It consisted of two parts:

Part I: concerned with personal data of head nurses such as (age, gender, marital status, nursing qualification, years of experience in hospital and years of experience in department).

Part II: This part intended to identify methods used by head nurses to manage nursing workload. It was consisted of 20 items.

Scoring system: Likert scale with three category was compressed for the purpose of presentation of each item; the responses from never to usually were scored respectively from $0-2,(0)$ never and (1) sometimes and (2) usually.

Preparatory phase: This phase started from April 2015 to the end September 2015 covering six months. It included a review of recent national and international related literature using journals, periodicals, textbooks, internet, and theoretical knowledge of the various aspects concerning the topic of the study. The investigator prepared the tools for data collection. Once ready, the tools were evaluated by five jury members: professor from Helwan University, professor and two assistant professors from Menoufiya University and assistant professor from Ain Shams University. They face the content validity of the tools aimed to judging its clarity, comprehensiveness, relevance, and accuracy. Modifications and rephrasing of some statements were done based experts opinions and translating three development tools into English language.

Pilot study: A Pilot study was conducted on about $10 \%$ of total sample 25 nurses and 4 head nurses. The aim was to examine the sequence of items, feasibility, practicability and applicability of the tool, clarity of the language and for estimating the time needed to fill it. The time required to fill the questionnaire sheet was from (10-15) minutes for each tool. The tools were finalized based on the results of the pilot study. The pilot studies were included in the sample. The pilot study also served to assess the reliability of data collection first tool reliability was $=r=0.91$ and $\alpha=0.93$, second tool reliability was $r=0.93$ and $\alpha=0.94$ and third tool reliability was $r=0.87$ and $\alpha=0.92$.

Field work: After securing necessary permissions, the investigator met the hospital administrator to explain the aim and process of the study and to gain their cooperation, the researcher started by introducing her to each group of nurses and gave explanations about 
the purpose of the study and getting agreement of nurses to participate in the research. Then, the researcher distributed the data collection forms with instructions about how to fill .The filled forms were collected in time and revised to check their completeness to avoid any missing data.

The data were collected according to type of work and work load of each department, sometimes it was in the middle of the shift and other time before the end of the shift after an oral permission obtained from studied sample. The field work lasted for three months from the beginning of October 2015 to the end of December 2015 The average number of nurses filled the questionnaire sheets were between 4-5 nurses per day.

Administrative design: An official letter requesting permission to conduct the study was issued from the Dean of faculty of nursing Benha University that were sent to the director of the hospital explaining the aim of the study. Then, the researcher met the hospital administrator, assured complete confidentiality of the obtained information and the study would not affect in any way the work.

\section{Ethical Considerations:}

Oral informed consents were obtained from the participants. They were informed about their rights to refuse or withdraw from the study with no consequences. They were reassured about the anonymity and confidentiality of the information collected, and would be used only for the purpose of scientific research. No harmful maneuvers were performed or used and no foreseen hazards were anticipated from conducting the study on participants

Statistical design: After completion of data collection, the data were organized and tabulated using Excel Computer Software Package, while statistical analysis was done using Statistical Package for the Social
Sciences (SPSS version 14.0). Data were presented using descriptive statistics in the form of frequencies and percentages for qualitative variables. Qualitative variables were compared using chi square test $\left(\mathbf{X}^{\mathbf{2}}\right)$ as the test of significance and correlation coefficient. Statistical significance level value was considered when $\mathrm{p}$ - value $<0.05$ and a highly significance level was considered when $\mathrm{p}$-value $<0.001$, while $\mathrm{p}$ value $>0.05$ indicates non-significant results.

\section{Results}

Table (1) shows that staff nurse age ranged between 20 to $\geq 35$ years. The majority of them $(83 \%)$ were females and nearly three quarter of them $(71.1 \%)$ were married. In relation to educational qualification nearly half of them $(49.4 \%)$ were nursing diploma. Regarding to their years of experience $(32.4 \% \& 37.2 \%)$ of nurses had 1-5 years of experience in hospital and department respectively.

Figure (1) illustrates that nearly half $49.4 \%$ of the staff nurses had low perception regarding to workload and $42.7 \%$ of them had moderate perception regarding to workload, while minority $7.9 \%$ of them had high perception regarding to workload.

Figure (2) illustrates that more than half $53.4 \%$ of the studied staff nurses had moderate perception regarding to causes and types of error, while minority $18.6 \%$ of them had low perception regarding to causes and types of error.

Table (2) describes head nurses age ranged between 20 to $\geq 36$. All of them $(100 \%)$ were females. The majority of them $(91.2 \%)$ were married. For their educational qualification two third of them $(67.6 \%)$ were bachelor of nursing. Regarding to their years of experience in hospital more than one third of them (38.2\%) had 6-10 years. and less than half of them (41.2\%) had 11-15 years of experience in departmental. 
Figure (3) demonstrates that all of studied head nurses $100 \%$ were used promoting performance level method to manage staff nurses workloads, while minority of them $5.9 \%$ were used formal policies and program method.
Table (3) shows correlation between nursing workload perception and nurses errors. This result demonstrated that there was significant positive correlation between nursing workload perception and nurses errors.

Table (1): Demographic characteristics of staff nurses in the studied sample $(n=253)$.

\begin{tabular}{|c|c|c|}
\hline Socio - demographic characteristics & Frequency & $\%$ \\
\hline \multicolumn{3}{|l|}{ Age in years } \\
\hline 20 & 92 & 36.4 \\
\hline 26 & 57 & 22.5 \\
\hline 30 & 64 & 25.3 \\
\hline$\geq 35$ & 40 & 15.8 \\
\hline Mean \pm SD & & \\
\hline \multicolumn{3}{|l|}{ Gender } \\
\hline Male & 43 & 17 \\
\hline Female & 210 & 83 \\
\hline \multicolumn{3}{|l|}{ Marital status } \\
\hline Single & 61 & 24.1 \\
\hline Married & 180 & 71.1 \\
\hline Divorced & 4 & 1.6 \\
\hline Widow & 8 & 3.2 \\
\hline \multicolumn{3}{|l|}{ Nursing qualification } \\
\hline Nursing diploma & 125 & 49.4 \\
\hline Nursing diploma + specialization & 50 & 19.8 \\
\hline Technical nursing education+ diploma & 74 & 29.2 \\
\hline Bachelor of nursing & 4 & 1.6 \\
\hline \multicolumn{3}{|l|}{ Years of experience in hospital } \\
\hline 1 & 82 & 32.4 \\
\hline 6 & 81 & 32 \\
\hline 11 & 38 & 15 \\
\hline$\geq 15$ & 52 & 20.6 \\
\hline Mean \pm SD & & \\
\hline \multicolumn{3}{|l|}{ Years of experience in department } \\
\hline 1 & 94 & 37.2 \\
\hline 6 & 79 & 31.2 \\
\hline 11 & 36 & 14.2 \\
\hline$\geq 15$ & 44 & 17.4 \\
\hline Mean \pm SD & & \\
\hline
\end{tabular}


Nurses Perception toward Nursing Workloads and its Effect on Nurses Errors at Benha University Hospital

Figure (1): Distribution of staff nurses perception regarding workload in the studied sample $(\mathrm{n}=\mathbf{2 5 3})$.

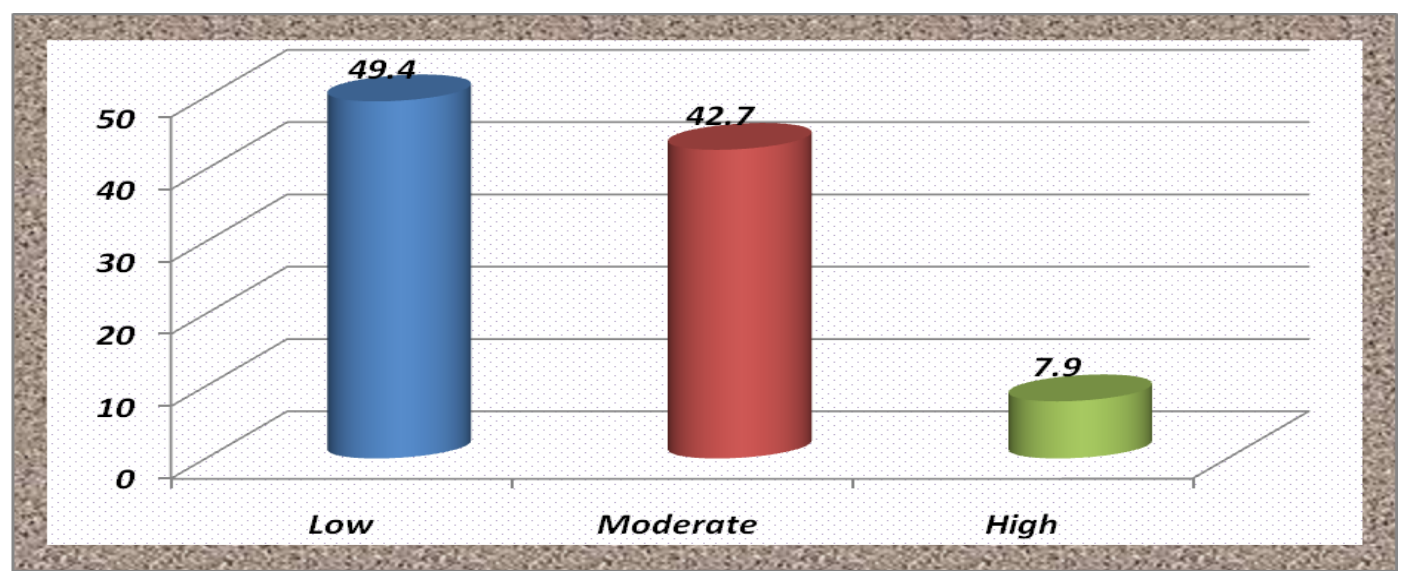

Figure (2): Distribution of staff nurses perception regarding causes and types of error in the studied sample $(n=253)$.

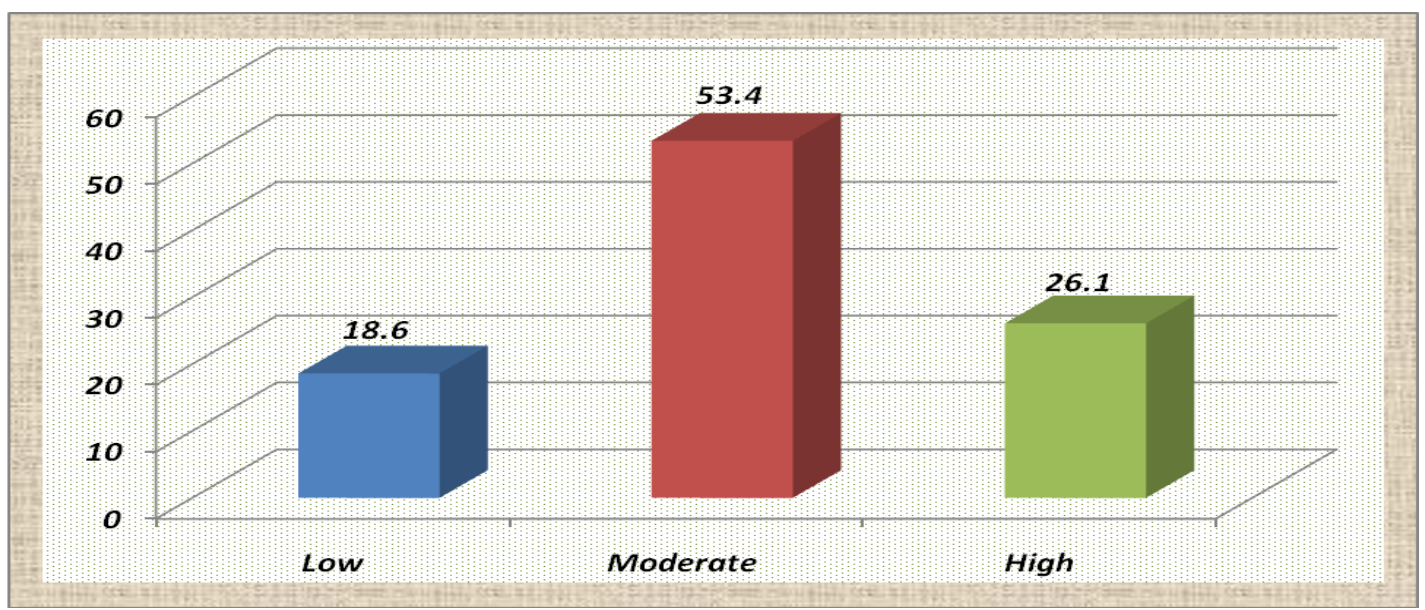


Table (2): Demographic characteristics of the studied head nurses in the studied sample $(n=34)$.

\begin{tabular}{|c|c|c|}
\hline socio - demographic characteristics & Frequency & $\%$ \\
\hline \multicolumn{3}{|l|}{ Age in years } \\
\hline $20-$ & 4 & 11.8 \\
\hline $26-$ & 13 & 38.2 \\
\hline $30-$ & 11 & 32.4 \\
\hline$\geq 36$ & 6 & 17.6 \\
\hline Mean \pm SD & & \\
\hline \multicolumn{3}{|l|}{ Gender } \\
\hline Male & 0 & .0 \\
\hline Female & 34 & 100 \\
\hline \multicolumn{3}{|l|}{ Marital status } \\
\hline Single & 0 & .0 \\
\hline Married & 31 & 91.2 \\
\hline Divorced & 1 & 2.9 \\
\hline Widow & 2 & 5.9 \\
\hline \multicolumn{3}{|l|}{ Nursing qualification } \\
\hline Secondary nursing education & 1 & 2.9 \\
\hline Technical nursing education & 10 & 29.4 \\
\hline Bachelor of nursing & 23 & 67.6 \\
\hline \multicolumn{3}{|l|}{ Years of experience in the hospital } \\
\hline $1-$ & 7 & 20.6 \\
\hline $6-$ & 13 & 38.2 \\
\hline $11-$ & 4 & 11.8 \\
\hline$\geq 15$ & 10 & 29.4 \\
\hline Mean \pm SD & & \\
\hline \multicolumn{3}{|l|}{ Years of experience in the department } \\
\hline $1-$ & 14 & 14.7 \\
\hline 6- & 9 & 26.5 \\
\hline $11-$ & 5 & 41.2 \\
\hline$\geq 15$ & 6 & 17.6 \\
\hline Mean \pm SD & & \\
\hline
\end{tabular}

Figure (3): Total head nurses methods disposition among studied head nurses in the studied sample $(\mathbf{n}=34)$.

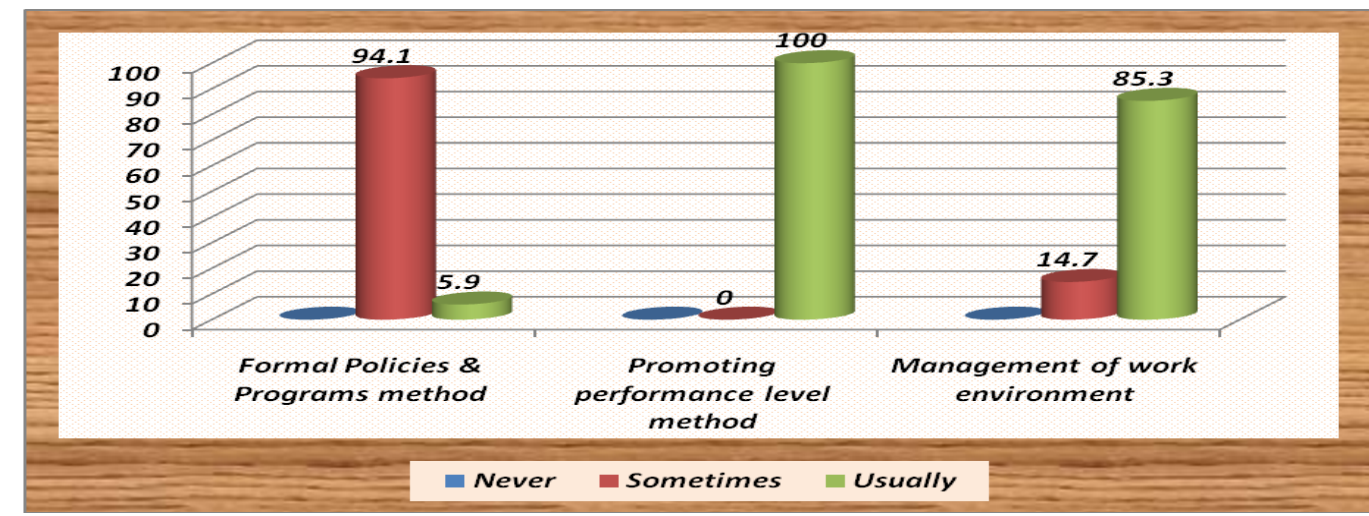


Table (3) Correlation between nursing workload perception and nurses errors

\begin{tabular}{|l|c|c|}
\hline \multirow{2}{*}{ Variables } & \multicolumn{2}{|c|}{ Nursing workload perception } \\
\cline { 2 - 3 } & $\mathbf{R}$ & P value \\
\hline Nurses errors & $.525(* *)$ & .000 \\
\hline
\end{tabular}

performance in a rural hospital" and stated

\section{Discussion}

The present study aimed to identify nurses perception toward nursing workloads and its effect on nurses errors at Benha University Hospital through assessing the workloads among staff nurses, Identifying the causes and types of staff nurses errors from their perspective and determining the methods used by head nurses to manage staff nurses workloads from their perspective.

As regards staff nurses demographic characteristics, the staff nurses age ranged between 20 to $\geq 35$ years, the majority of them were females, nearly three quarters of them were married, nearly half of them had secondary nursing education and their work experience were 1-5 years. These results matched with Bahadori et al., (2014), who studied "Factors Affecting Intensive Care Units Nursing Workload" and reported that the majority of sample were females, married and had less than 6 years job experience.

However these results disagreed with result of Topalhan et al., (2015), who studied "Workload perception, a study among emergency department healthcare workers", and found that more than two thirds of studied sample were males, the majority of them had a baccalaureate degree and their work experience were 1-10 years.

The findings of the present study revealed that the majority of staff nurses had low perception related to workload while minority of them had high perception related to workload. This finding disagreed with result of Asamani et al., (2015) who studied "The influence of workload levels on that the workload levels of health workers were perceived as moderate, however a significant inter professional difference exists in which nurses perceived and having the highest workload followed by paramedics support staff and doctors.

The findings of the present study revealed that more than half of the studied staff nurses had moderate perception regarding causes and types of error. This result supported by Eslamian et al., (2010) who studied" Assessing the nursing error rate and related factors from the view of nursing staff " and reported that the highest rate of error had been related to lack of compiling and reviewing the history of the patients consumed medicines, lack of observing the appropriate time for prescribing the medicines and lack of assessing the lab tests of patient with regard to its dependent medicines.

As regards head nurses demographic characteristics, result showed that head nurse age ranged between 20 to $\geq 36$, all of them were females and the majority of them were married, for their educational qualification two thirds of them had bachelor of nursing degree. Regarding to their years of experience in hospital more than one third of them had 6-10 years and less than half of them had $11-15$ years of experience in departmental. This result agreed with Alghamdi, (2016) who studied "Nursing workload a concept analysis" and stated that all of studied sample were females, the majority of them were married, for their educational qualification majority of them were bachelor of nursing degree and their work experience $\geq 10$ years. 
Concerning to head nurses methods disposition among studied head nurse the present study demonstrated that all of studied head nurses used promoting performance level method to manage staff nurses workloads, while minority of them were used formal policies and program method. This may be due to continuous communication with staff nurses, assessing efficiency and quality of nurses performance periodically and provide accurate and realistic information about job demands and expectations.

Results of the current study revealed that there was highly statistically significant positive correlation between nursing workload perception and nurses errors this mean when workload perception increased nursing error increased. This finding was in accordance with Trinier, (2016), who studied "nursing workload and its relationship to patient care error in the pediatric critical care setting" and reported that there was a statistically significant association between nursing workload hours and patient care error was identified and the odds of error increased as the nursing workload increased.

\section{Conclusion}

The present study was conducted to identify nurses perception toward nursing workloads and its effect on nurses errors at Benha University Hospital through, assessing the workloads among staff nurses, identifying the causes and types of staff nurses errors from their perspective and determining the methods used by head nurses to manage staff nurses workloads. The result of present study was concluded that:

- Staff nurses had low perception related to nursing workload

- Staff nurses had moderate perception related to causes and types of error.
- All studied head nurses used promoting performance level method to manage staff nurses workloads.

- There was significant positive correlation between nursing workload perception and nurses errors.

\section{Recommendations}

In the light of the findings obtained from the present study, the following points are recommended:

\section{* Nursing level:}

- Team atmosphere and team building is very important factor in managing workload cooperation and coordination among nurses.

- Instruct and encourage nurses about the importance of early reporting of errors without fearing of punishment.

- Balanced time schedule to assure workload distribution.

- Effective delegation and open communication from head nurse and staff nurse.

- A clear written job description should be provided for all categories of nurses.

\section{* Educational level:}

- Continuous education program for nurses to update their knowledge and skills in order to give quality of nursing care for avoiding the errors related to under staffing.

\section{References}

Alghamdi, M. (2016): Nursing Workload a concept analysis, University of San 
Diego, Journal of Nursing Management, 24 (4), P:7.

Ali, A. (2002): the effect of workload on nurses error, master thesis, faculty of nursing, Zagazig University, nursing administration department, pp: 2-7.

Al-Kandari, F. \& Thomas, D. (2008): Adverse nurse outcomes correlation to nurses workload, staffing, and shift rotation in Kuwaiti hospitals, Applied Nursing Research, 21(3), pp.139-146.

Al-Maani, A. (2006): Analysis of Work Stress among Nursing Staff at JUH,Field Study, Faculty of Business Administration, Jordan University, $2^{\text {nd }}$ Ed, pp: 355-378.

Amaar,T.\& Aboelrose ,s.(2006): The effect of some the internal variables on job stress level of the administrative board and academic universities, master thesis, Business administration department ,Palestinian, Gaza Strip, pp:119-120.

Armstrong, F., \& Reale, E. (2009): Ensuring quality, safety and positive patient outcomes, $3^{\text {rd }}$ ed., Australian Nursing Federation, Australia, pp. 18-31.

Asamani, J. Amertil, N, \& Chebere, M. (2015): The influence of workload levels on performance in a rural hospital British, Healthcare Management Journal 21 (12), p. 583

Bahadori, M., Ravangard,R., Raadabadi, M., Mosavi, S., Fesharaki, M. \& Mehrabian, F. (2014): Factors Affecting Intensive Care Units Nursing Workload, Iranian Red Crescent Medical Journal ,16(8), p.112

Benner, P., Malloch, K., Bitz ,k., Emrich, L., Thomas, M., Bowen, K., Scott, K., Patterson,L.,Schwed, K. \&, Farrell, M.(2010): Creating a National Database on nursing errors journal, 7 (1), p.52.
Borowski, R. (2013): Dynamic Patient Events and Impact on Nursing Workload, Ohio State University, chapter II, pp. 57-8, available at : https://kb.osu.edu/dspace/bitstream/.../Ra chel Borowski_thesise .pdf

Carayon, P.\& Gurses AP.( 2014): Nursing workload and patient safety, a human factors engineering perspective. In Hughes RG, Patient safety and quality,availableonlineathttp://www.ncbi. nlm.nih.gov/books/NBK657/nurseshdbk/ nurseshdbk.pdf. Accessed in March / 2016.

Environmental evaluation for work place violence in health care and social services, Journal of safety research, 39(5), pp: 237-250.

Eslamian ,J ., Taheri, F., Bahrami, M .\& Mojdeh ,S.(2010): Assessing the nursing error rate and related factors from the view of nursing staff, Iran Journal of Nursing Midwifery Research, 15(11) pp. 272-277.

Esmaeilil, R., Moosazadeh,M., Alizadeh, M.\& Afshari, M.(2015): a systematic review of the workload of nurses in intensive care units using NAS, Acta Medica Mediterranea journal, 31(11),pp. 1455:1458.

Hoonakker,P., Carayon,P., Gurses ,A., Brown ,R., McGuire ,K., Khunlertkit ,A.\& M. Walker ,J.(2012): Measuring Workload of ICU Nurses With A Questionnaire Survey, The Nasa Task Load Index , 1(2), pp:131-143.Available at: https:/ /www. ncbi.nlm .nih.gov/pmc/articles/PMC3388621/.

Accessed on 2-30/ June/2016

Mcphaul, M., Murrett, K., Flannery, K., Rosen, J., \&Lipscomb, J. (2008):

Samra, J., Gilbert, M., Shain, M. \& Bilsker, D. (2012): workload management Centre 
for Applied Research in Mental Health and Addiction, available at: II www.workplacestrategiesformentalhealth .com/ota) pp: 1-3

Sujata , S. ,Nawin, P., Chandan, S.\&Sagar, G. (2011):Drug prescribing pattern and prescription error in elderly, a retrospective study of inpatient record, Asian Journal of Pharmacy and Clinical Research; 4(3), pp: 129-132.

Topalhan,T., Bayat, B., Kavalcı, C., Kayımmaz ,A.\& Findik ,M.( 2015 ): Workload perception, A study among emergency department healthcare workers, International Journal of Multidisciplinary Research and Development, 2(3) pp: 519-521.

Trinier, R.(2016): nursing workload and its relationship to patient care error in the pediatric critical care setting, a master thesis, faculty of health disciplines, Athabasca university, Canada, p:5.

White, L., Duncan, G. \& Baumle, W. (2011): Foundation of Nursing, $3^{\text {rd }}$ ed, Australia, Cengage,

pp:

173-190. 